\title{
SYLVIA PLATH E ROLAND BARTHES: FRAGMENTOS DE UM DIÁRIO AMOROSO
}

Beatriz Viana Lopes Saltarelli*

RESUMO: Este ensaio traz uma discussão sobre Os diários de Sylvia Plath tomando como base alguns conceitos propostos por Roland Barthes. Procuramos discutir aqui a questão de Eros que pode se dar em uma relação escritor/ escritura e quais as características marcantes nessa relação. Uma relação que vai muito além do simples ofício da escrita e que pode ser mesmo equiparada a uma relação amorosa.

PALAVRAS-CHAVE: Roland Barthes; Sylvia Plath; diários; Morte do autor.
* beatrizsaltarelli@gmail.com

Mela UFMG.

ABSTRACT: This paper brings a discussion of The Journals of Sy/via Plath, based on some concepts proposed by Roland Barthes. Here, we discuss the question of Eros that can happen in a relationship writer / write and what the striking features in this relationship. A relationship that goes far beyond the simple craft of writing and can even be equated to a loving relationship.

KEYWORDS: Roland Barthes, Sylvia Plath, Journals, Death of the autor. 
1. BARTHES. Fragmentos de um discurso amoroso, p. 49.

2. HUGHES. Prefácio, p. 22.

3. Expressão usada por Barthes no texto Aula: "a escritura se encontra em toda parte onde as palavras têm sabor (saber $\mathrm{e}$ etimologia). Curnon, a mesma nunária, é preciso dizia que, na culinária, é preciso que as colsas tenh a po gosto que são. as coisas se torner, para que as coisas se tónen é necue săo, ingrediente, o sal das palavras. É esse gosto das palavras que faz saber profundo, fecundo" (p. 21) grifos meus.

4. BARTHES. O rumor da língua, $p$. 66.
CATÁstrofe. Crise violenta no curso da qual o sujeito, experimentando a situação amorosa como um impasse definitivo, uma armadilha da qual não poderá jamais sair, se vê fadado a uma destruição total de si mesmo.

Em um de seus mais difundidos textos, Barthes nos fala sobre a morte do autor. E, se existe uma escritora que tem uma relação quase intrínseca com a morte, essa é Sylvia Plath. Seja pelo suicídio cometido aos 30 anos de idade ou pela natureza extrema de seus poemas. Parece que quanto mais se fala sobre o assunto mais duvidas e questionamentos surgem. Ou, como ressalta Frieda Hughes - filha de Sylvia - no prefácio de Ariel: "Desde que ela morreu, ela tem sido dissecada, analisada, reinterpretada, reinventada, ficcionalizada e, em alguns casos, completamente fabricada". ${ }^{2}$ No entanto, neste ensaio a ideia é discutir uma Plath para além da morte. Não queremos desvendar suas razões para se matar através de seus poemas como tem sido feito com afinco ou encontrar confissões em seus textos. Não nos interessa aqui a morte do corpo, porque isso seria reduzir a linguagem de seus escritos, mas sim a morte em favor da literatura. Ou, a vida que a autora construiu para e pela escritura. Indo além, o apagamento da vida em prol do sabor da linguagem. ${ }^{3}$

Para este ensaio tomaremos como base Os diários de Sylvia Plath. Ora, por que a escolha dos diários se, assim como na visão de Mallarmé, queremos "suprimir o autor em proveito da escritura?”. ${ }^{4}$
Atualmente existe uma proliferação de biografias no mercado editorial e cada vez mais estudos sobre biografias, autobiografias, destaques para arquivos de escritores e gêneros confidenciais e também uma superexposição através de blogs e internet. Por si só esse fato já traz relevância para o estudo dos diários para a teoria literária.

Enquanto Blanchot afirma que "o que impulsiona o artista não é diretamente a obra, é sua busca, o movimento que conduz a ela". ${ }^{5}$ Barthes destaca que a "obra se escreve procurando a obra", ${ }^{6}$ que só se escreve mesmo em algum lugar intermediário entre o desejo de escrever e a decisão de escrever. Também confirma o mesmo conceito num texto sobre Flaubert: "escrever é viver [...], a escrita é o próprio fim da obra, não a sua publicação".

Por isso a escolha dos diários - que foram mantidos por longos anos - como objeto principal dessa discussão, nos quais estão documentadas sensações dessa procura incessante pela obra. Em diversas passagens a autora fala sobre a importância da escrita, de se tornar uma escritora reconhecida e publicada e também da necessidade de escrever. Também em outros trechos ela destaca a importância do diário como instrumento necessário à própria vida: "Suponho que o simples fato de eu ser capaz de escrever aqui, segurando a caneta, prove minha capacidade de seguir vivendo". ${ }^{\circ}$
5. BLANCHOT. O livro por vir, p. 291

6. BARTHES. Crítica e verdade, p. 18.

7. BARTHES. O grau zero da escrita p. 163.

8. PLATH. Os diários de Sylvia Plath, p. 387.
EM TESE
BELO HORIZONTE
v. 21
N. 2
MAIO-AG0. 2015
SALTARELLI. Sylvia Plath e Roland Barthes: fragmentos de um diário amoroso P. 186-195 
9. BARTHES. O rumor da língua, p. 66 .

10. Cf.: NIETZSCHE. Ecce Homo, p. 96

11. É possível observar referências ao filósofo em alguns escritos de Barthes, como nesse trecho de Aula: "Infelizmente a linguagem humana é sem exterior: é um lugar fechado. Só se pode sair dela pelo preço do impossível: pela singularidade mística, tal como a descreve Kierkegaard, (...); ou então pelo amen nietzschiano, que é como uma sacudida jubilatória dada ao servilismo da língua, àquilo que Deleuze chama de 'capa reativa'. Mas a nós, que não somos nem cavaleiros da fé nem superhomens, só resta, por assim dizer, trapacear com a língua, trapacear a língua. Essa trapaça salutar, essa esquiva, esse logro magnífico que permite ouvir a língua fora do poder, o esplendor de uma revolução permanente da linguagem, eu a chamo quanto a mim: literatura".

12. BARTHES. O grau zero da escrita p. 75 .
Além disso, é o próprio Barthes quem também destaca o ponto de destaque recebido pelo autor:

O autor é uma personagem moderna, produzida sem dúvida por nossa sociedade na medida em que [...] ela descobriu o prestígio do indivíduo ou, como se diz mais nobremente, da "pessoa humana". [...] O autor reina ainda nos manuais de história literária, nas biografias de escritores, nas entrevistas dos periódicos, e na própria consciência dos literatos, ciosos por juntar, graças ao seu diário íntimo, a pessoa e a obra; a imagem da literatura que se pode encontrar na cultura corrente está tiranicamente centralizada no autor, sua pessoa, sua história, seus gostos, suas paixões. ${ }^{9}$

Sendo assim, não podemos ignorar algo que é parte essencial de uma cultura. Estudar um diário é estudar também a história. Não os fatos históricos como algo idealizado, mas sim aquilo que há de mais humano na história: as emoções de uma vida. Como afirma Nietzsche, só o espírito que é livre pode se desprender dos ideais e ver as coisas humanas, demasiado humanas. ${ }^{10}$

E, além de tudo, o diário de uma escritora pode nos trazer pistas sobre o trabalho pela busca das fronteiras da linguagem, porque em uma posição de concordância com Nietzsche, ${ }^{11}$ Barthes também afirma que uma obra-prima moderna é impossível. ${ }^{12}$ De maneira que, não há humanismo poético na modernidade: esse discurso de pé é um discurso cheio de terror, isto é, coloca o homem em ligação não com outros homens, mas com as imagens mais desumanas da Natureza; o céu, o inferno, o sagrado, a infância, a loucura, a matéria pura, etc. ${ }^{13}$

É nos Diários de Plath que podemos encontrar também o registro de uma vida que é marcada pela necessidade vital da escrita. Mais do que o desejo de ser uma autora reconhecida, a escrita permeava todos os acontecimentos da vida de Sylvia: "Como ele poderia entender que justifico minha vida, minhas emoções ardentes, meu sentimento, ao passá-lo para o papel?". ${ }^{14} \mathrm{E}$ Barthes também destaca esse ponto que atinge certos escritores: "o que o segura (aos seus próprios olhos) não é o que ele escreveu, mas a decisão obstinada de o escrever". ${ }^{15}$

Ou seja, ser escritor não é apenas uma ocupação ou uma profissão. É algo que vai além. Algo da ordem da responsabilidade, pois, "para o escritor, a verdadeira responsabilidade é a de suportar a literatura como um engajamento fracassado" ${ }^{16}$ Responsabilidade maior consigo do que com o mundo, uma vez que "a escrita é uma realidade ambígua: por uma parte nasce incontestavelmente de um confronto do escritor com a sua sociedade" ${ }^{17}$ E Plath também menciona esse conflito permanente e angustiante com a sociedade ao expressar: "Eu também quero ser importante. Sendo diferente. E essas garotas são todas iguais”. ${ }^{18}$
13. BARTHES. O grau zero da escrita, p. 45

14. PLATH. Os diários de Sy/via Plath, p. 36.

15. BARTHES. Crítica e verdade, p. 17.

16. BARTHES. Crítica e verdade, p. 35

17. BARTHES. O grau zero da escrita, p. 15

18. PLATH. Os diários de Sy/via Plath, p. 230.
EM TESE
BELO HORIZONTE
v. 21
N. 2
MAIO-AGO. 2015
SALTARELLI. Sylvia Plath e Roland Barthes: fragmentos de um diário amoroso P. 186-195 
19. BARTHES. O grau zero da escrita, p. 162

20. BARTHES. O grau zero da escrita p. 163.

21. BARTHES. Crítica e verdade, p. 20
A partir dessa discussão podemos pensar no tipo de relação que existe entre o escritor e a escrita. Naquilo que Barthes, ao analisar Flaubert e Proust, cita como um processo atroz do escritor, no qual este está o tempo todo em busca, sempre escrevendo, enclausurado na linguagem, na própria escritura: "Esse circuito sisifeano é chamado por Flaubert com uma palavra muito forte: é atroz, única recompensa que recebe pelo sacrifício de uma vida toda". ${ }^{19} \mathrm{E}$ ainda reforçado, no mesmo texto pela máxima: "escrever é viver" ${ }^{20}$

Ninguém pode escrever sem tomar apaixonadamente partido, ${ }^{21}$ é o que afirma Barthes. Ora, podemos então começar a perceber algo da dimensão amorosa na escritura. Afinal existe uma relação. De necessidades e sentimentos. É antes pelo sentir que se escreve. Talvez por isso alguns escritores tenham algo de extremo em seus escritos. Talvez pela exacerbação dos sentimentos. Sabemos que em Plath, esse fato não é só verdadeiro como determinante, uma vez que ela foi tantas vezes, rejeitada por causa de sua linguagem violenta e natureza extrema, como podemos observar nas seguintes passagens:

Minha tarefa inicial é abrir a experiência real, como uma ferida antiga; depois ampliá-la; depois inventar a partir de uma pena esvoaçante o pássaro colorido, completo.

(...) Devo desprezar o mercado e os veículos, para enviar coisas que escrevo nas quais nada há de sincero e realmente proveitoso.
(...) Escreverei histórias malucas. Mas sinceras. Conheço o horror dos sentimentos primais, das obsessões. ${ }^{22}$

Se é pelo sentir que se escreve, como afirma Barthes, a mensagem não é nada mais do que aquilo que arde em nós, "não há outro significado primeiro da obra literária senão um certo desejo: escrever é um modo do Eros". ${ }^{23}$ Sendo assim, precisamos então entender como essa questão erótica se faz presente na literatura.

No entanto, antes de falar de questões eróticas precisamos, em primeiro lugar, conhecer o mito de Eros:

[...] antes do surgimento de Eros, a humanidade se compunha de três sexos: o masculino, o feminino e o andrógino. Os seres andróginos eram redondos e possuíam quatro mãos, quatro pernas, duas faces, dois genitais, quatro orelhas e uma cabeça. Esses seres, por sua própria natureza se tornaram muito poderosos e resolveram desafiar os deuses, sendo por isso, castigados por Zeus, que decidiu cortá-los em duas partes. (...) os novos seres, mutilados e incompletos, passaram a procurar suas metades correspondentes. (...) E daí se originou Eros, o impulso para "recompor a antiga natureza" e "restaurar a antiga perfeição". ${ }^{24}$

Para entender melhor esse processo de completude do Eros, podemos tomar como base alguns conceitos da
22. PLATH. Os diários de Sy/via Plath, p. 589; 590; 591.

23. BARTHES. Crítica e verdade, p. 21
EM TESE
BELO HORIZONTE v. 21
MAIO-AG0. 2015
SALTARELLI. Sylvia Plath e Roland Barthes: fragmentos de um diário amoroso P. 186-195
24. BRANCO. O que é erotismo, p. 9-10 
28. BRANCO. Chão de letras, p. 56, grifo meu. psicanálise. De acordo com as bases da teoria psicanalítica a mulher é marcada, antes de tudo, pela falta. Segundo Freud a sexualidade começa na infância, quando a criança passa por fases e fatores que terão implicações sobre toda a vida sexual. E é nessa fase que a questão da falta começa a permear a mulher, com efeitos e consequências do mito de Édipo que, para Freud, se constitui como o fenômeno central do período sexual da primeira infância e também do Complexo de castração. De acordo com essas ideias, na infância a menin se reconheceria em comparação ao menino, como castrada, uma vez que não possui o pênis.

Serge André destaca as reflexões de Freud em torno da feminilidade sob uma identidade faltosa, pois enquanto o falo funciona como referência única, a feminilidade só pode se colocar como incerta. Dessa forma, destituída de uma identidade inicial, a mulher só consegue apreender a feminilidade indiretamente, em comparação ao outro.

O mesmo autor também chama atenção para a problemática do Édipo feminino, uma vez que não é possível determinar se a relação da menina com o pai pode realmente ser um substituto equivalente para a relação com a mãe. Se "no menino o complexo de Édipo se dissolve sob o efeito do complexo de castração, o da menina é tornado possível e introduzido pelo complexo de castração". ${ }^{25}$ Assim, o próprio complexo de Édipo feminino é "produzido" a partir da falta
E pela ausência do falo e o desejo de alcançá-lo que ela faz sua nova escolha objetal, passando da mãe para o pai.

Não só Freud define a mulher como um ser de falta, mas segundo Barthes, a própria sociedade a marca como tal "Historicamente o discurso da ausência é sustentado pela Mulher: a Mulher é sedentária, o Homem é caçador, viajante; a Mulher é fiel (ela espera), o homem é inconstante (ele navega, corre atrás de rabos-de-saia). É a Mulher que dá forma à ausência" ${ }^{26}$

Ora, se a mulher é permeada pela falta não é de se estranhar que a escrita que tomamos como tipicamente femini$\mathrm{na}^{27}$ também tenha essas características. Com base nesses conceitos, podemos perceber que essa questão da erótica talvez se faça ainda mais evidente em tal escrita. De acordo com Branco a partir da leitura de diversos textos de autoria feminina, pôde-se verificar como eles se distinguiam dos demais, possuindo tom, dicção, respiração e ritmo próprios. Assim, podemos perceber que tal escrita se constitui exatamente num discurso construído a partir da perda.

Desconexo, descompassado, abrupto, sôfrego (...) o texto terminará por se construir em torno da lacuna (...), da falta, do vazio e muitas vezes do silêncio. Embora, em sua grande parte, o texto pareça falar e falar e não querer outra coisa senão falar. Mas essa fala excessiva, esse discurso tagarela, antes adorna o vazio que o preenche, antes margeia a lacuna que a obtura. ${ }^{28}$
26. BARTHES. Fragmentos de um discurso amoroso, p. 36.

27. Cf.: BRANCO. O que é escrita feminina.

5. ANDRÈ. O que quer uma mulher?, p. 27.
EM TESE
BELO HORIZONTE
v. 21
N. 2
MAIO-AGO. 2015
SALTARELLI. Sylvia Plath e Roland Barthes: fragmentos de um diário amoroso P. 186-195 
29. BRANCO. A mulher escrita, p. 160.

30. LACAN. O seminário: livro 20 , p. 98.

31. ANDRÈ. O que quer uma mulher, p. 333.
Branco ainda chama atenção para uma preferência em tal escrita pelos chamados gêneros do impossível: diários, cartas, memórias e autobiografias. "E quem sabe assim se explique a frequência com que as mulheres se dedicaram a essa escrita particularmente íntima, peculiarmente corporal, como a do diário. (...) Por esse motivo talvez se possa dizer que a escrita do diário é, por excelência, feminina”. ${ }^{29}$

Ainda tomando como base a teoria psicanalítica, Lacan aprofunda as teorias sobre a sexualidade de Freud e afirma que a mulher se situa como não toda na função fálica. Por isso, por ser destituída de significante ele afirma que não pode existir $A$ mulher: "só que A mulher, isto só se pode escrever barrando-se o A. Não há A mulher, artigo definido para designar o universal. Não há A mulher pois por sua essência ela não é toda”. ${ }^{30}$

Serge André faz ainda um paralelo com a teoria de Lacan e retoma a questão proposta por Freud afirmando que "o que uma mulher quer é que alguma coisa advenha ao lugar deste significante faltoso, que um ponto de apoio lhe seja fornecido precisamente lá onde o inconsciente a deixa abandonada". ${ }^{31}$

Ora, agora podemos pensar que se a mulher é não toda ela também pode ser outra. É justamente pela falta de significante que a mulher se coloca nesse lugar além, tão além que às vezes não cabe em si. Assim, podemos relacionar a "falta" à busca incessante pela obra também ao processo de busca de completude de Eros. "Outro desses processos - e talvez o mais poderoso, porque menos facilmente manipulável e, por isso, mais ameaçador à ordem social - é a arte" ${ }^{32}$ Bataille destaca ainda que o erotismo trata-se de um aspecto interior da vida do homem, "esse objeto responde à interioridade do desejo" ${ }^{33}$

Nesse ponto chegamos a uma questão crucial deste ensaio. Ora, se o erotismo é algo interior e se a arte pode se configurar como um desses processos, podemos agora confirmar que essa relação entre o escritor e a escrita, traga a possibilidade de uma experiência erótica. Uma experiência interna, mas que só pode se realizar quando externada. Experiência esta entre o "eu que escreve" e o que não escreve. Entre o que Barthes nomeia de escritor/ escrevente. Ou, como encontramos em um registro de Plath: "Eu o amo porque você sou eu... minha escrita, meu desejos de muitas vidas". ${ }^{34}$

Nessa relação que agora podemos chamar amorosa, percebemos que existem algumas características específicas como o tempo no qual o escritor está inscrito. Aquele tempo já mencionado anteriormente, localizado em algum lugar intermediário entre o desejo - de escrever - e a decisão - da escrita. "É que o tempo do escritor não é um tempo diacrônico, mas um tempo épico; sem presente e sem passado, ele
32. BRANCO. O que é erotismo, p. 12

33. BATAILLE, O erotismo, p. 53.

34. PLATH. Os diários de Sy/via Plath, p. 35.
EM TESE
BELO HORIZONTE
v. 21
N. 2
MA10-AGO. 2015
SALTARELLI. Sylvia Plath e Roland Barthes: fragmentos de um diário amoroso P. 186-195 
35. BARTHES. Crítica e verdade, p. 18 grifo meu.

36. ROLLYSON. Ísis Americana, p. 127.

37. BARTHES. Fragmentos de um discurso amoroso, p. 91. está inteiramente entregue a um arrebatamento cujo objetivo, se pudesse ser conhecido, pareceria tão irreal aos olhos do mundo". ${ }^{35}$

Apesar de esse tempo ser desconhecido, a questão do arrebatamento é determinante. O mesmo arrebatamento que toma conta de um amante, de alguém que se encontra profundamente enamorado. Deve ser por isso que, enquanto leitores, somos também, às vezes, arrebatados por certos livros, uma vez que o que se lê é da ordem do sentir, daquilo que se encontra também ardente em nós. E provavelmente por esse mesmo sentir que em uma carta para a mãe, Aurélia, Plath afirma que: "escrever é a primeira paixão da minha vida". ${ }^{36}$

Também é pelo desejo amoroso que tantas vezes encontra-se a ambiguidade da relação entre escritor-mundo. Pois se existe uma inconformidade com o mundo, muitas das vezes existe também o desejo de ser reconhecido no mundo como um ser da arte. Dessa forma, surge a inquietação interna: "O que o mundo, o que o outro vai fazer de meu desejo? Essa a inquietude em que se encontram todos dos movimentos do coração, todos os 'problemas' do coração". ${ }^{37}$ Nos diários de Plath, isso pode ser observado quando a autora descreve o desejo desesperado - nas palavras dela - de ser publicada por uma revista. Por mais que, por vezes, ela considerasse que o mundo não estava à sua altura, ela ainda buscava reconhecimento externo da mesma maneira que o enamorado busca ser correspondido pelo objeto de sua paixão: "Além disso, dependo desesperadamente de tornar meus poemas, meus pobres poemas loquazes, menores e bem-arrumados, aceitos pela New Yorker" ${ }^{38}$

Mais uma ideia trabalhada por Barthes de uma escrita erótica diz respeito à linguagem dos amantes: “a linguagem é uma pele: fricciono minha linguagem contra o outro. Como se eu tivesse palavras à guisa de dedos, ou dedos na ponta de minhas palavras. Minha linguagem treme de desejo". ${ }^{39}$ Ou seja, uma linguagem na qual as palavras tomam forma, na qual as palavras têm sabor. Sabor ardente, de desejo. Pensando nisso, é fácil perceber porque Plath sente-se estéril quando se encontra sem criatividade. Porque a linguagem fala ao mesmo tempo, no corpo e para o corpo. Porque para escritores assim, é a palavra que alimenta; a alma e o corpo: "Sinto-me pouco criativa. Estou seca, seca e estéril. Preciso produzir". 40

Temos ainda a questão da solidão. Não é raro ver escritores solitários, considerados pelo mundo como desajustados, “o desclassificado, aquele que não está 'religado' a nenhum ser além dele mesmo" ${ }^{41}$ Ora, se o objeto amoroso do escritor é a própria escrita é exatamente por isso que ele não está ligado a outro, mas em uma busca por si. No entanto, essa busca é ambígua, pois é interna, mas só se concretiza quando
38. PLATH. Os diários de Sy/via Plath, p. 232.

39. BARTHES. Fragmentos de um discurso amoroso, p. 99

40. PLATH. Os diários de Sylvia Plath, p. 317

41. BARTHES. Fragmentos de um discurso amoroso, p. 316.
EM TESE
BELO HORIZONTE
v. 21
N. 2
MAIO-AGO. 2015
SALTARELLI. Sylvia Plath e Roland Barthes: fragmentos de um diário amoroso P. 186-195 
42. PLATH. Os diários de Sy/via Plath, p. 103.

43. BARTHES. Fragmentos de um discurso amoroso, p. 157.

44. BARTHES. Fragmentos de um discurso amoroso, p. 159; 161 é exteriorizada, por meio da obra. E podemos pensar que é dessa mesma solidão que Sylvia escreve em um trecho do diário: "Se não tiver esse período para ser eu mesma, para ficar aqui sozinha, escrevendo, de certo modo perderia minha integridade, inexplicavelmente". ${ }^{42}$

Outro ponto relevante é a necessidade de escrever sobre o ser amado: "Engodos, debates e impasses provocados pelo desejo de 'exprimir' o sentimento amoroso numa 'criação' (particularmente de escrita)". ${ }^{43}$ No caso dessa vivência do Eros pelo escritor isso pode ser veementemente observado, uma vez que surge, muitas vezes, o anseio de escrever sobre a própria escrita. Não raro são os casos de autores que expressam sua relação com a própria escrita em suas obras.

Sou ao mesmo tempo grande demais e fraco demais para a escrita: estou ao lado dela, que é sempre rigorosa, violenta, indiferente ao eu infantil que a solicita. $\mathrm{O}$ amor tem decerto um pacto com minha linguagem (que o mantém), mas não pode alojar-se em minha escrita.

(...)

Saber que não escrevemos para o outro, saber que essas coisas que vou escrever jamais me farão amado de quem amo, saber que a escrita não compensa nada, não sublima nada que ela está precisamente ali onde você não está - é o começo da escrita. ${ }^{44}$
Voltemos agora ao início, na epígrafe que abre esse texto. O que poderia ser considerado uma catástrofe real para um escritor? Podemos encontrar alguma pista sobre isso na mais recente biografia escrita sobre a Plath, na qual Rollyson destaca a necessidade vital da escrita para a escritora: "Quando sucumbiu a um bloqueio criativo pela primeira vez, no verão de 1953, Sylvia o encarou como uma morte em vida e tentou pôr fim à própria existência". ${ }^{45}$

Ou seja, o que desencadearia em um escritor uma crise violenta, que poderia levar até à destruição de si mesmo? Para escritores que escrevem acompanhados de Eros, nessa experiência tão passional com seu objeto amoroso, provavelmente a falta da escrita. Talvez por isso tão poucos escritores sejam corajosos como Rimbaud ao tomar a decisão de não mais escrever: "eis por que tão poucos escritores renunciam a escrever, pois isso significa literalmente matar-se, morrer para ser o que escolheram; e se esses escritores existem, seu silêncio ressoa como uma conversão inexplicável (Rimbaud)". ${ }^{46}$

É por isso que aqui não nos interessamos em discutir o suicídio. Porque a verdadeira catástrofe de Plath, não foi a morte, mas sim a vida. A vida em situação extrema. A catástrofe interna: "situações definitivas, sem retorno: projetei-me no outro com tal força que, quando este me falta, não posso me reencontrar, me recuperar: estou perdido para sempre". ${ }^{47}$
45. ROLLYSON. Ísis Americana, p. 31.

46. BARTHES. Crítica e verdade, p. 35

47. BARTHES. Fragmentos de um discurso amoroso, p. 50. 
Plath passou a vida perdida. E o único modo de sobreviver era escrever. Ela sobreviveu e a resposta dessa sobrevivência é a intensidade que pode ser sentida em seus escritos e a vida subestimada em função da escritura. A verdade é que no final "pouco interessa se a arte, enfim, lhe foi salvação ou perdição. A positividade da arte está em ser ela testemunho vivo, vibrante e irrefutável de embriaguez, excesso, audácia aprofundamentos e desencaixes do homem". ${ }^{4}$

\section{REFERÊNCIAS}

ANDRÈ, Serge. $\mathbf{O}$ que quer uma mulher? Trad. Dulce Duque Estrada. 2a ed. Rio de Janeiro: Zahar, 2011

BATAILLE, Georges. 0 erotismo. Trad. Fernando Scheibe. $1^{\text {a }}$ ed. Belo Horizonte: Autêntica, 2014.

BARTHES, Roland. Aula. Trad. L Leyla Perrone-Moisés. São Paulo: Editora Cultrix.

BARTHES, Roland. Crítica e verdade. Trad. Leyla PerroneMoisés. São Paulo: Perspectiva, 2007.

BARTHES, Roland. Fragmentos de um discurso amoroso. Trad. Márcia Valéria Martinez de Aguiar. São Paulo: Martins Fontes, 2003

BARTHES, Roland. 0 grau zero da escrita: seguido de novos ensaios críticos. Trad. Mario Laranjeira. São Paulo: Martins Fontes, 2004
BARTHES, Roland. O rumor da língua. Trad. Mario Laranjeira. São Paulo: Editora Brasiliense, 1988

BLANCHOT, Maurice. O livro por vir. Trad. Leyla Perone-Moisés. 2a ed. São Paulo: Editora WMF Martins Fontes, 2013.

BRANCO, Lucia Castello. Chão de letras: as literaturas e a experiência da escrita. Belo Horizonte: Editora UFMG, 2011.

BRANCO, Lucia Castello. O que é erotismo. São Paulo: Brasiliense, 1984

BRANCO, Lucia Castello. O que é escrita feminina. São Paulo: Brasiliense, 1991

BRANCO, Lucia Castello; BRANDÃO, Ruth Silviano. A mulher escrita. Rio de Janeiro: Lamparina editora, 2004.

FREUD, Sigmund. Um caso de histeria, três ensaios sobre a sexualidade e outros trabalhos. Rio de Janeiro: Imago, 2006.

FREUD, Sigmund. Obras completas, volume 16: O eu e o id "autobiografia" e outros textos (1923 - 1925). Trad. Paulo Césa de Souza. São Paulo: Companhia das letras, 2011.

HUGHES, Frieda. Prefácio. In: PLATH, Sylvia. Ariel. Edição restaurada e bilíngue. Trad. Rodrigo Garcia Lopes e Maria Cristina Lenz de Macedo. 2a ed Campinas: Verus Editora, 2010.

LACAN, Jacques. O seminário. Livro 20. Mais, ainda. $2^{\mathrm{a}}$ edição. Rio de Janeiro: Zahar, 1985. 
NIETZSCHE, Friedrich Wilhelm. Ecce homo: de como a gente se torna o que é Porto Alegre: L\&PM, 2014.

NOBRE, Renarde Freire. O amor artístico. Belo Horizonte (Inédito).

PLATH, Sylvia. Ariel. Edição restaurada e bilíngue. Trad. Rodrigo Garcia Lopes e Maria Cristina Lenz de Macedo. $2^{\text {a }}$ ed. Campinas: Verus Editora, 2010

PLATH, Sylvia. Os diários de Sylvia Plath - 1950-1962. Editado por Karen V. Kukil. Trad. Celso Nogueira. São Paulo: Globo, 2004.

ROLLYSON, Carl. Ísis americana: a vida e a arte de Sylvia Plath Rio de Janeiro: Bertrand Brasil, 2015. 